\title{
Epidemiology of Postmenopausal Osteoporosis and Related Risk Factors in Female Residents of Tashkent and Namangan (Republic of Uzbekistan)
}

\author{
S. I. Ismailov, L.S. Abboskhodjaeva, N.M. Alikhanova \\ Center for the Scientific and Clinical Study of Endocrinology, Uzbekistan Public Health Ministry \\ Tashkent, Uzbekistan
}

\begin{abstract}
Our epidemiological survey is the first step in studying prevalence and risk factors of postmenopausal osteoporosis (PMO) in the Republic of Uzbekistan, aiming at development of early preventive and therapeutic measures to reduce osteoporosisassociated fractures.

Methods: We screened 1378 postmenopausal female residents of Tashkent and Namangan, two cities with the largest populations in Uzbekistan, aged from 50 to 80 . The duration of the postmenopausal period was $\geq 1$ year.

Results: According to our data, the prevalence of osteoporosis in different regions of Uzbekistan varies widely (33.5\% and $51.1 \%$ in Tashkent and Namangan, respectively). The prevalence of osteoporosis increases with age from 25.6\% (50 to 59 years) to $51.3 \%$ (in $>70$ age group) in Tashkent and from $44.0 \%$ to $80.0 \%$ in the same age groups in Namangan.

There were significantly more women in Namangan with body mass $<57 \mathrm{~kg}$ than in Tashkent (OR 2.44; 95\%CI 1.72-3.46; $P<0.00001)$. We found that the number of women doing physical exercises in Tashkent was 2 times more than in Namangan (65.5\% versus $36.1 \%$, OR 3.36 ; $95 \%$ CI $2.64-4.27 ; P<0.0001)$.

Conclusion: Our research shows that osteoporosis is widely spread among women above 50 living in two big densely populated cities of Uzbekistan (Tashkent and Namangan). Low body mass and irregular physical activity, fracture history, and duration of menopause are the factors of risk in the studied cohorts of women.
\end{abstract}

Keywords: menopause; risk factors; osteopenia; osteoporosis.

\section{Introduction}

Postmenopausal osteoporosis (PMO) is a systemic, multifactorial skeletal disease occurring in women in postmenopause as a consequence of deficiency of sexual hormones, mainly estrogens. The disease is characterized by progressive loss of bone mass and change in microstructure, resulting in increased risk of fracture, morbidity, and mortality. PMO constitutes up to $80 \%$ to $85 \%$ of all types of osteoporosis [1-3]. Osteoporosis frequency in all skeletal sites increases with age; thus, according to WHO, osteoporosis is registered in $70 \%$ of women older than 80 years [4]. Findings from epidemiological studies in the Russian Federation demonstrated that in the age group of $\geq 50$

*Corresponding author: Prof. Said I. Ismailov, PhD, ScD. Director of the Center for the Scientific and Clinical Study of Endocrinology, Tashkent, Uzbekistan.E-mail: ismailov.said@list.ru years, according to WHO criteria, osteoporosis occurred in $30.5 \%$ to $33.1 \%$ of women and in $22.8 \%$ to $24.1 \%$ of men, totaling 10 million people [5], which means that 1 woman out of 5 and 1 man out of 3 have osteoporosis. Similar data were published on prevalence of osteoporosis among women of the white population of North America and a number of countries of Western Europe [6-8]. Frequency of osteopenia and osteoporosis among perimenopausal female residents of Tashkent is $55.7 \%$ and $12.2 \%$, respectively [9]. But no epidemiological studies of postmenopausal osteoporosis have been conducted in the Republic of Uzbekistan so far.

According to the U.S. Census Bureau International Database, in 2014 the population of Uzbekistan was 29 million people, $17 \%(4.2 \mathrm{mln})$ and $3.4 \%(971,000)$ of people being $\geq$ 50 and $\geq 70$ years of age, respectively. By 2050 in the face of a general population rise to 35 million people, $40 \%$ (14mln) and $12 \%(4.2 \mathrm{mln})$ are expected to be $\geq 50$ and $\geq 70$ years of age, respectively. No specially designed epidemiological studies of 
osteoporosis and osteoporotic fractures have been conducted. However, according to the Research Institute of Traumatology and Orthopedics, there are at least 30,000 people with osteoporosis and 150,000 with osteopenia in Uzbekistan. The number of patients with osteoporosis and osteopenia is predicted to increase up to 250,000 by 2020 .

Our epidemiological survey is the first step in studying prevalence and risk factors of postmenopausal osteoporosis in the Republic of Uzbekistan, aiming at development of early preventive and therapeutic measures to reduce osteoporosisassociated fractures.

The work was initiated to study prevalence and various risk factors of postmenopausal osteoporosis among female residents of Tashkent and Namangan.

\section{Materials and methods}

We screened 1378 postmenopausal female residents of Tashkent and Namangan, two cities with the largest populations in Uzbekistan, aged from 50 to 80 . The duration of the postmenopausal period was $\geq 1$ year. The groups were comparable by parameters. Duration of osteoporosis and menopause $\geq 1$ year was the inclusion criterion. Diseases affecting bone metabolism, such as hyperparathyroidism, thyrotoxicosis, Itsenko-Cushing's syndrome and disease, hypogonadism in medical history, rheumatic disorders, malabsorption syndrome, renal insufficiency, hepatic dysfunction, and malignancies, as well as prior treatment with medications affecting calcium metabolism 12 months before the study, were the exclusion criteria.

The study was conducted in accordance with the ethical principles stated in Declaration of Helsinki of 1964 (revised in Seoul in 2008). The trail is registered on www. who.int/bulletin/ archives/79(4)373; http://www.wma.net/en/30publications $/ 10$ policies $/ \mathrm{b} 3 /$. The study was approved by the Center for the Scientific and Clinical Study of Endocrinology Ethics Committee. Written informed consent was obtained from all participants. A special questionnaire chart was developed in the Center and was filled out for each woman. The chart included demographic and anthropometric data (age, height, weight), gynecological and hormonal history (age of menarche, age of menopause, the number of children, reproductive history), private and familial history of fractures, the present way of life (physical activity, smoking, drinking, and everyday use of dairy products).

Bone mineral density (BMD) was measured by ultrasound osteodensitometry (Omnisense 8000, Sunlight, Israel).

According to clinical guidelines, diagnosis of osteoporosis or osteopenia was based on the values of a T-score, the number of standard deviations (SD) from age norm. Thus, osteoporosis was diagnosed with T-score of $2.5 \mathrm{SD}$, the parameter's range from $>-2.5 \mathrm{SD}$ to $\leq 1.0 \mathrm{SD}$ determined osteopenia, and the value $<-1.0 \mathrm{SD}$ was taken as normal. Every patient filled in a card-questionnaire developed at the Center for the Scientific and Clinical Study of Endocrinology, Uzbekistan Public Health Ministry.

Results were statistically processed using Excel 2010 and the software package STATISTICA 6.0 (Stat Soft, 2001). Logistic regression was used to calculate OR and 95\% CI. Quantitative parameters are presented as $\mathrm{M} \pm \mathrm{SD}$, as well as Median $(\mathrm{Me})$ and $25^{\text {th }}$ and $75^{\text {th }}$ percentiles as Inter Quartile Range (IQR). We used the Chi-square test to compare observed data. $P$ values of $<0.05$ were considered statistically significant.

\section{Results}

We screened 1378 postmenopausal women aged $\geq 50$ years (mean age $57.9 \pm 6.4$ years, IQR 53.0 to 62.0) within the period from 05.01.2010 to 05.01.2011. Residents of Tashkent were placed into Group $1(\mathrm{n}=963)$, and residents of Namangan into Group $2(\mathrm{n}=415)$. Among the examinees $371(26.9 \%)$ women had normal BMD (nBMD), while osteopenia and osteoporosis were diagnosed in 473(34.3\%) and $534(38.8 \%)$ examinees, respectively (Table 1).

Table 1.

Characteristics of women in Tashkent and Namangan

\begin{tabular}{|c|c|c|c|c|c|c|}
\hline \multirow[t]{2}{*}{ Variable } & \multicolumn{2}{|c|}{$\begin{array}{c}\text { Tashkent } \\
\mathrm{n}=963\end{array}$} & \multicolumn{2}{|c|}{$\underset{n=415}{\text { Namangan }}$} & \multicolumn{2}{|c|}{$\begin{array}{c}\text { Total } \\
\mathrm{n}=1,378\end{array}$} \\
\hline & $\mathrm{n}$ & $\%$ & $\mathrm{n}$ & $\%$ & $\mathrm{n}$ & $\%$ \\
\hline nBMD & 296 & 30.7 & 75 & 18.1 & 371 & 26.9 \\
\hline Osteopenia & 345 & 35.8 & 128 & 30.8 & 473 & 34.3 \\
\hline Osteoporosis & 322 & 33.5 & 212 & 51.1 & 534 & 38.8 \\
\hline \multicolumn{7}{|l|}{ Age } \\
\hline 50-59 year & 555 & 57.6 & 327 & 78.8 & 882 & 64.0 \\
\hline $60-69$ year & 330 & 34.3 & 68 & 16.4 & 398 & 28.9 \\
\hline$\geq 70$ year & 78 & 8.1 & 20 & 4.8 & 98 & 7.1 \\
\hline Weight $<57 \mathrm{~kg}$ & 74 & 7.7 & 70 & 16.8 & 144 & 10.4 \\
\hline $\mathrm{BMI}<20.0 \mathrm{~kg} / \mathrm{m}^{2}$ & 15 & 1.6 & 11 & 2,7 & 26 & 1.9 \\
\hline $\begin{array}{l}\text { Daily } \\
\text { consumption of dairy } \\
\text { products }\end{array}$ & 208 & 21.6 & 90 & 21.7 & 298 & 21.6 \\
\hline $\begin{array}{l}\text { Regular physical } \\
\text { activity (not less than } \\
30 \text { min per day) }\end{array}$ & 631 & 65.5 & 150 & 36.1 & 781 & 56.7 \\
\hline Cigarette smoking & 26 & 2.7 & & & 26 & 1.9 \\
\hline $\begin{array}{l}\text { Consumption } \\
\text { coffee }\end{array}$ & 52 & 5.4 & 41 & 9.9 & 93 & 6.7 \\
\hline Previous fracture & 16 & 1.7 & 25 & 6.0 & 41 & 3.0 \\
\hline Age, year & \multicolumn{2}{|c|}{$59.9 \pm 6.4$} & \multicolumn{2}{|c|}{$55.5 \pm 5.8^{*}$} & \multicolumn{2}{|c|}{$57.9 \pm 6.4$} \\
\hline Me: IQR & \multicolumn{2}{|c|}{$\begin{array}{c}58.0 \\
54.0: 63.0\end{array}$} & \multicolumn{2}{|c|}{$\begin{array}{c}54.0 \\
50.0: 59.0\end{array}$} & \multicolumn{2}{|c|}{$\begin{array}{c}57.0 \\
53.0: 62.0\end{array}$} \\
\hline BMI & \multicolumn{2}{|c|}{$29.7 \pm 5.3$} & \multicolumn{2}{|c|}{$28.9 \pm 5.5^{*}$} & \multicolumn{2}{|c|}{$29.5 \pm 5.4$} \\
\hline Me: IQR & \multicolumn{2}{|c|}{$\begin{array}{c}29.3 \\
26.1: 32.9\end{array}$} & \multicolumn{2}{|c|}{$\begin{array}{c}28.3 ; \\
25.3: 32.3\end{array}$} & \multicolumn{2}{|c|}{$\begin{array}{c}28.9 \\
26.0: 32.7\end{array}$} \\
\hline T-score & \multicolumn{2}{|c|}{$-1.86 \pm 1.5$} & \multicolumn{2}{|c|}{$-2.34 \pm 1.52 *$} & \multicolumn{2}{|c|}{$-2.00 \pm 1.54$} \\
\hline Me: IQR & \multicolumn{2}{|c|}{$\begin{array}{c}-1.89 \\
-2.91:-0.78\end{array}$} & \multicolumn{2}{|c|}{$\begin{array}{c}-2.60 \\
-3.60:-1.20\end{array}$} & \multicolumn{2}{|c|}{$\begin{array}{c}-2.05 \\
-3.10:-0.90\end{array}$} \\
\hline $\begin{array}{l}\text { Duration of } \\
\text { menopause, year }\end{array}$ & \multicolumn{2}{|c|}{$10.8 \pm 8.2$} & \multicolumn{2}{|c|}{$9.4 \pm 7.1 *$} & \multicolumn{2}{|c|}{$10.4 \pm 7.9$} \\
\hline Me: IQR & \multicolumn{2}{|c|}{$\begin{array}{c}10.0 \\
4.0: 16.0\end{array}$} & \multicolumn{2}{|c|}{$\begin{array}{c}8.0 \\
4.0: 14.0\end{array}$} & \multicolumn{2}{|c|}{$\begin{array}{c}9.0 \\
4.0: 15.0\end{array}$} \\
\hline Weight, kg & \multicolumn{2}{|c|}{$75.3 \pm 13.8$} & \multicolumn{2}{|c|}{$70.0 \pm 13.7^{*}$} & \multicolumn{2}{|c|}{$73.7 \pm 14.0$} \\
\hline Me: IQR & \multicolumn{2}{|c|}{$\begin{array}{c}74.0 \\
65.4: 84.8\end{array}$} & $\begin{array}{r}65 \\
60.0\end{array}$ & & $\begin{array}{r}7 \\
64 .\end{array}$ & \\
\hline
\end{tabular}


The maximum number of women with nBMD was found in the age group of 50 to 59 years $(80.6 \%)$. With ageing, a progressive reduction in the percentage of patients with normal parameters was observed: $17.5 \%$ and $1.89 \%$ in the age groups of 60 to 69 and 70 to 79 years, respectively. In women with osteopenia the tendency persists, but there were significantly fewer women aged from 50 to 59 years in the osteopenia group than in the group with nBMD (62.8\% versus $80.6 \%$; OR $0.41 ; 95 \%$ CI $0.30-0.56 ; P<0.0001)$. There were significantly more women aged from 60 to 69 (OR 2.0; 95\%CI $1.43-2.79 ; P<0.0001)$ and from 70 to 79 (OR 4.16; 95\%CI $1.82-9.47 ; P<0.0001)$ years in the group with osteopenia than in the group with nBMD.

In the osteoporosis group there were confidently fewer women aged from 50 to $59(53.6 \%)$ than in the group with nBMD (OR 0.28; 95\%CI 0.2-0.38; $P<0.0001$ ) and in the group with osteopenia (OR 0.68; 95\%CI 0.53-0.88; $P<0.0001$ ). However, among examinees with osteoporosis there were confidently fewer women aged from 60 to $69(36.0 \%)$ than in the group with nBMD (OR 2.64; 95\%CI 1.92-3.64; $P<0.0001)$ and in the osteopenia group (OR 1.32; 95\%CI 1.01-1.72; $P=0.05)$.

About $10.5 \%$ of women with osteoporosis belonged to the 70- to 79-year-old group; they were confidently more in number than in the group with nBMD (OR 6.09; 95\%CI, $2.74-13.5 ; P<0.0001)$ and more, though not confidently, than in the group with osteopenia (OR 1.47; 95\%CI 0.94-2.28; $\mathrm{P}=0.11)$. As to residency, there were confidently fewer women with nBMD in Namangan than in Tashkent (18.1\% versus $30.7 \%$, OR $0.50 ; 95 \%$ CI $0.37-0.66 ; P<0.0001)$. In addition, osteoporosis in Group 2 was found in $51.1 \%$ of examinees from Namangan versus $33.5 \%$ in those from Tashkent (OR 2.08; 95\%CI 1.64-2.63; $P<0.0001$ ) (Fig. 1).

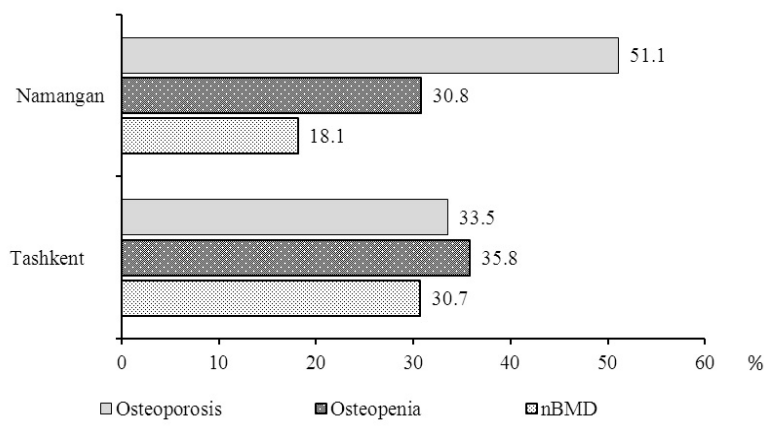

Figure 1. Frequency of BMD disorders among residents of Tashkent and Namangan

Namangan residents in the 50 to 59 and the 60 to 69 age groups were 1.5 and almost 5 times less than Tashkent residents, respectively. Similarly, a low frequency of nBMD could be seen in women aged from 70 to 79 . Prevalence of osteopenia was found not to depend on age in Tashkent residents. The number of osteopenia cases confidently reduced among examinees from Namangan. With ageing, the number of women with osteoporosis was found to increase in both cities, but among Namangan residents the number was almost 2 times more. Thus, osteoporosis frequency was higher in the
Namangan group than in the Tashkent group. In Namangan, nBMD was found in fewer female residents, and osteoporosis frequency was higher.

By means of analysis of BMD dependence on age, we found that the mean age of the examinees was $57.9 \pm 6.4$ years; the Tashkentian examinees were significantly older than Namanganians (59.9 \pm 6.4 versus $55.5 \pm 5.8)$. This tendency was confirmed by more detailed analysis of the dependence of the degree of BMD on age. However, despite the fact that among examinees in the second group osteopenia and osteoporosis frequencies were higher, the women on average were 3 to 6 years younger than those in the first group.

There were significantly more women in Namangan with weight $<57 \mathrm{~kg}$ than in Tashkent (OR 2.44; 95\%CI 1.723.46; $P<0.00001$ ) (Fig.2.). There were more patients with low $\mathrm{BMI}$ in the cohort of Namangan residents with osteopenia and osteoporosis. Comparative analysis of parameters in the two cities demonstrated more women with lower limit of weight in Namangan. This seems to be the cause of higher osteopenia and osteoporosis in Group 2. We have found no substantial differences in the rate of $\mathrm{BMI}<20.0 \mathrm{~kg} / \mathrm{m}^{2}$ in the studied cohort of women (OR 1.72; 95\%CI 0.78-3.78; $P=0.25$ ). Neither irregular administration of calcium nor smoking made a significant difference.

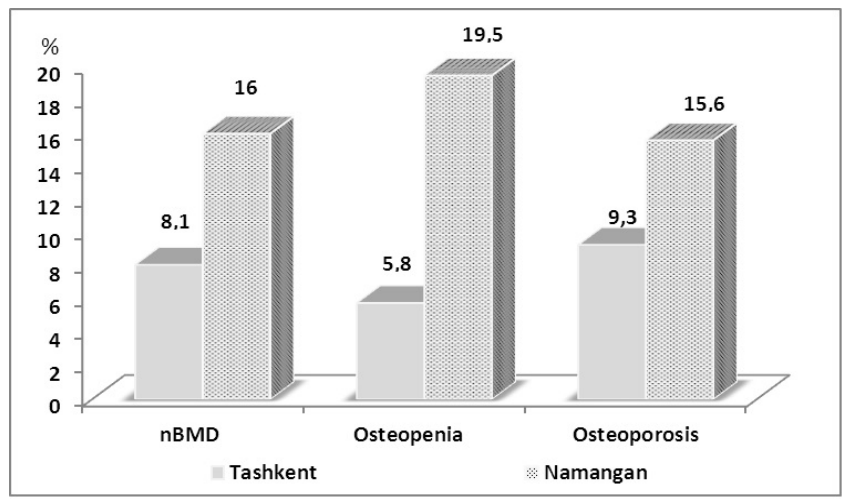

Figure 2. The percentage of women with weight less than $57 \mathrm{~kg}$ depending on the bone mineral density

Regular physical activity among women with osteoporosis was significantly rarer than in women with nBMD (48.1\% versus $64.4 \%$, OR 0.51 ; 95\%CI $0.39-0.67$; $P<0.0001)$. At the same time, the number of women doing physical exercises in Tashkent was 2 times more than in Namangan $(65.5 \%$ versus $36.1 \%$, OR 3.36 ; 95\%CI $2.64-$ 4.27; $P<0.0001)$. Tashkent female residents with osteoporosis were physically active more regularly than Namangan female residents (62.4\% versus 26.4\%, OR 4.63; 95\%CI 3.17-6.76; $P<0.0001)$. In Namangan, the percentage of physically active women in the osteoporosis group $(26.4 \%)$ was confidently lower than those in nBMD group $(49.3 \%$, OR 0.37 ; $95 \% \mathrm{CI}$ $0.21-0.64 ; P<0.0001)$ and in the osteopenia group $(44.5 \%$, OR $0.45 ; 95 \%$ CI $0.28-0.71 ; P<0.0001)$.

We studied osteoporosis frequency by duration of menopause. In Namangan, there were more women with menopause onset before 45 years of age than in Tashkent 
(30.8\% versus $14.2 \%$, OR $2.69 ; 95 \%$ CI $2.04-3.54 ; P<0.0001)$. There were many more nBMD women with a menopause duration less than 5 years compared to PMO women $(45.0 \%$ versus $20.8 \%$ OR $3.13 ; 95 \%$ CI $2.26-4.32 ; P<0.0001)$. It was much more frequent among residents from Tashkent (52.4\% versus $15.2 \%$, OR $6.09 ; 95 \%$ CI $3.98-9.32 ; P<0.0001)$ than from Namangan ( $30.1 \%$ versus $31.7 \%$, OR 0.93 ; $95 \%$ CI $0.54-$ $1.59 ; P=0.89$ ). Osteoporosis was confidently more frequent among patients with menopause duration more than 10 years (51.7\% versus $14.3 \%$, OR $6.11 ; 95 \%$ CI $4.61-8.11 ; P<0.0001)$.

\section{Discussion}

Osteoporosis has become a major public health concern, which leads to increased rates of morbidity and mortality. Epidemiological investigations have shown that there is no country, nationality or race free from osteoporosis. According to NHANES data, there are 14 million women in the US aged more than 50 with low hip bone density. Prevalence of osteoporosis in all parts of the skeleton rises with age. According to WHO data, it exists in $70 \%$ of women more than 80 years old [10]. The disorder is being diagnosed in all age groups (from $6 \%$ in individuals $>50$ years to $50 \%$ among individuals $>80$ years) [11]. A recent study on the epidemiology of osteoporosis in the United States found a prevalence of $15.4 \%$ among women older than 50 years and a prevalence of $34.9 \%$ among women older than 80 years [12].

According to our data, the prevalence of osteoporosis in different regions of Uzbekistan varies widely $(33.5 \%$ and $51.1 \%$ in Tashkent and Namangan, respectively). The prevalence of osteoporosis increases with age from $25.6 \%$ (50 to 59 years) to $51.3 \%$ (in $>70$ age group) in Tashkent and from $44.0 \%$ to $80.0 \%$ in in the same age groups in Namangan.

Low weight or low BMI is an indicator of low mineral density of bone tissue and a predictor of future fractures, particularly of the hip. Low BMI is $<20 \mathrm{~kg} / \mathrm{m}^{2}$, low BMD $<57 \mathrm{~kg}[13,14]$. Our data show that there were many more residents with body mass $<57 \mathrm{~kg}$ in Namangan, than in Tashkent, but there was no difference in the number of residents with $\mathrm{BMI}<20 \mathrm{~kg} / \mathrm{m}^{2}$.

A low intake of calcium can lead to increased resorption of the bone matrix with demineralization and a consequent increase in fracture risk [1]. There were an equal number of women in studied cohorts using dairy products.

Persistent low physical activity is known to facilitate osteoporosis in older years. A sedentary style of life and immobilization result in rapid bone mass loss associated with accelerated bone resorption and slow bone formation [15]. Our study showed that the number of women doing physical exercises in Tashkent was 2 times more than in Namangan (65.5\% versus $36.1 \%$, OR 3.36; 95\% CI 2.64-4.27; $P<0.0001$ ).

According to Van Geel [16,17], the risk of refracture increases if the previous fracture took place less than 5 years ago. According to our data from two densely populated regions, fractures occurred much more frequently in Namangan (6.02\% versus $1.7 \%$, OR 3.79; 95\%CI 2.0-7.18; $P<0.0001)$.

Menopause and its duration is the most significant osteoporosis risk factor. After the onset of menopause, bone mass loss is nearly $2 \%$ to $3 \%$ a year up to the age of 65 to 70 , the rate subsequently reducing to $0.3 \%$ to $0.5 \%$ a year [18]. We found that the frequency of women with nBMD substantially decreases as the duration of menopause increases.

\section{Conclusion}

Our research shows that osteoporosis is widely spread among women above 50 living in two big densely populated cities of Uzbekistan (Tashkent and Namangan). Osteoporosis prevalence among Namangan female residents is higher than among Tashkent residents (51.1\% versus 33.5\%), the former being 3 to 6 years younger than the latter. Low body mass and irregular physical activity, fracture history, and duration of menopause are the factors of risk in the studied cohorts of women.

\section{Competing interests}

The authors declare that they have no competing interests.

\section{References}

1. Baccaro LF, Conde DM, Costa-Paiva L, Pinto-Neto AM. The epidemiology and management of postmenopausal osteoporosis: a viewpoint from Brazil. Clin Interv Aging 2015; 10:583-91.

2. Kim MY, Im SW, Park HM.The demographic changes of menopausal and geripausal Women in Korea. J Bone Metab 2015; 22(1):23-8.

3. Matin N, Tabatabaie O, Keshtkar A, Yazdani K, Asadi $\mathrm{M}$. Development and validation of osteoporosis prescreening model for Iranian postmenopausal women. J Diabetes Metab Disord 2015; 14:12.

4. Hodgson SF, Watts NB, Bilezikian JP, Clarke BL, Gray TK, Harris DW, et al. American Association of Clinical Endocrinologists medical guidelines for clinical practice for the prevention and treatment of postmenopausal osteoporosis: 2001 edition, with selected updates for 2003. Endocr Pract 2003; 9(6):544-64.

5. Toroptsova NV, Nikitinskaya OA, Demin NV, Benevolenskaya LI. Prevention of post-menopausal osteoporosis: results of three-year observation. Sci Prac Rheum 2006; 5:25-32. [Article in Russian].

6. Barrett-Connor E1, Siris ES, Wehren LE, Miller PD, Abbott TA, Berger ML, et al. Osteoporosis and fracture risk in women of different ethnic groups. J Bone Miner Res 2005; 20(2):185-94

7. Cauley JA1, Palermo L, Vogt M, Ensrud KE, Ewing S, Hochberg M, et al. Prevalent vertebral fractures in black women and white women. J Bone Miner Res 2008; 23(9):1458-67.

8. Lansdown D1, Bennet B, Thiel S, Ahmed O, Dixon L, Vokes TJ. Prevalence of vertebral fractures on chest radiographs of elderly African American and Caucasian women. Osteoporos Int 2011;22(8):2365-2371

9. Kandiloytu AYu. Osteopenic syndrome in per-menopausal female residents of Tashkent, its correction. Abstract of $\mathrm{PhD}$ Thesis. Tashkent; 2005. [in Russian].

10. Aggarwal N1, Raveendran A, Khandelwal N, Sen RK, Thakur JS, Dhaliwal LK, et al. Prevalence and related risk factors of osteoporosis in peri- and postmenopausal Indian women. J Midlife Health 2011; 2(2):81-5. 
11. Rahmani P, Morin S. Prevention of osteoporosis-related fractures among postmenopausal women and older men. CMAJ 2009; 181(11): 815-20.

12. Wright NC1, Looker AC, Saag KG, Curtis JR, Delzell ES, Randall S, et al. The recent prevalence of osteoporosis and low bone mass in the United States based on bone mineral density at the femoral neck or lumbar spine. J Bone Miner Res 2014; 29(11):2520-6.

13. Brown JP, Josse RG; Scientific Advisory Council of the Osteoporosis Society of Canada. 2002 clinical practice guidelines for the diagnosis and management of osteoporosis in Canada. CMAJ 2002;167 (10 Suppl):S1-34

14. De Laet C, Kanis JA, Oden A, et al. Body mass index as a predictor of fracture risk: a meta-analysis. Osteoporosis Int. 2005;16(11): 1330-1338.
15. Bonaiuti D, Arioli G, Diana G, Franchignoni F, Giustini A, Monticone $\mathrm{M}$, et al. Rehabilitation treatment Guidelines in postmenopausal and senile Osteoporosis. Eura Medicophys 2005; 41(4):315-37.

16. van Geel TA1, Geusens PP, Nagtzaam IF, van der Voort DJ, Schreurs CM, Rinkens PE, et al. Risk factors for clinical fractures among postmenopausal women: a 10-year prospective study. Menopause Int 2007; 13(3):110-5.

17. van Geel TA, Nguyen ND, Geusens PP, Center JR, Nguyen TV, Dinant GJ, et al. Development of a simple prognostic nomogram for individualising 5-year and 10-yearabsolute risks of fracture: a population-based prospective study among postmenopausal women. Ann Rheum Dis 2011;70(1):92-7.

18. Rojinskaya LYa. Systemic osteoporosis. Moscow, "Mokeev" Publishing House; 2000. [in Russian]. 